\title{
Comparison of Soil Biological Properties and Bacterial Diversity in Sugarcane, Soybean, Mung Bean and Peanut Intercropping Systems
}

\author{
Shangdong Yang ${ }^{1,2}$, Jian Xiao ${ }^{1}$, Ziyue Huang ${ }^{1}$, Renliu Qin ${ }^{1}$, Weizhong $\mathrm{He}^{3}$, Limin Liu ${ }^{3}$, Hongjian Liu ${ }^{3}$, \\ Aomei $\mathrm{Li}^{3} \&$ Hongwei $\mathrm{Tan}^{2}$ \\ 1 Agricultural College, Guangxi Key Laboratory of Subtropical Bio-resource Conservation and Utilization, \\ Guangxi University, Nanning, China \\ ${ }^{2}$ Guangxi Key Laboratory of Sugarcane Genetic Improvement, Guangxi Academy of Agricultural Sciences, \\ Nanning, China \\ ${ }^{3}$ Sugarcane Research Institute, Guangxi Academy of Agricultural Sciences, Nanning, China \\ Correspondence: Hongwei Tan, Guangxi Academy of Agricultural Sciences, Nanning 530007, P.R. China. Tel: \\ 86-0771-318-6568. E-mail: hongwei_tan@163.com
}

Received: June 8, 2021

Accepted: July 2, $2021 \quad$ Online Published: July 15, 2021

doi:10.5539/jas.v13n8p54

URL: https://doi.org/10.5539/jas.v13n8p54

The research is financed by National Natural Science Foundation of China (31760368), State Key Laboratory of Conservation and Utilization of Subtropical Agro-bioresources open fund (OSKL201506), Guangxi Key Laboratory of Sugarcane Genetic Improvement open fund (16-K-04-01), National Key R\&D Program of China (2018YFD0201100, 2018YFD0201103) and National technical position of sugar industry (Ratoon cultivation of sugarcane, 2017-2020, CARS-170206).

\begin{abstract}
Sugarcane intercropping with soybean [Glycine max (Linn.) Merr.], mung bean [Vigna radiata (Linn.) Wilczek] and peanut (Arachis hypogaea Linn.) as well as a sugarcane monoculture were conducted to study the impacts of intercropping on soil biological characteristics and bacterial diversity. The results showed that soil cultivable microorganisms, the activities of soil enzymes and microbial biomass carbon, nitrogen, and phosphorus were all significantly improved by intercropping with soybean and mung bean. Additionally, soil bacterial diversity and richness in sugarcane fields were also significantly enhanced by intercropping with soybean and mung bean. In addition, soil bacterial community structures in sugarcane fields can be altered by intercropping with different legumes. Proteobacteria, a high-nutrient-tolerant bacterial assemblage, became the dominant bacteria in the sugarcane-soybean and sugarcane-mung bean intercropped soils. Twenty four, 28, 26 and 27 dominant soil bacterial genera were found after the sugarcane-soybean, sugarcane-mung bean, sugarcane-peanut and sugarcane monoculture treatments, respectively. Sugarcane-mung bean intercropping being the most promising system for regaining and improving soil fertility and soil heath and facilitate agriculture intensification of sugarcane.
\end{abstract}

Keywords: sugarcane (Saccharum officinarum L.), legume crop, soil enzymes, bacterial diversity

\section{Introduction}

Sugarcane (Saccharum officinarum L.) is the primary source of sugar and is also utilized as a major biofuel and bioenergy crop worldwide (Tomes et al., 2011; Chandel et al., 2012). China is the third largest sugar producing country in the world after Brazil and India. In China, approximately $90 \%$ of sugarcane crops are planted in the southern and southwest regions, which are mainly in Guangxi, Guangdong, and Yunnan Provinces. Among these provinces, Guangxi Province is the top sugarcane and sugar producer and accounts for more than $65 \%$ of the total sugar production in China $(\mathrm{Li}, 2004)$. In China, sugarcane production is largely confined to hilly terrain under rainfed conditions that result in relatively low yields. The problem is worsened by the long-term overuse of chemical fertilizers and pesticides to improve cane and sugar yields (Robinson et al., 2011). For example, higher amounts of $\mathrm{N}$ fertilizer, as high as $600-800 \mathrm{~kg} \mathrm{~N} \mathrm{ha}^{-1}$ in some regions, are applied annually to sugarcane crops in China, while only 60-120 $\mathrm{kg} \mathrm{N} \mathrm{ha}^{-1}$ are applied in Brazil (Li \& Yang, 2014). Long-term chemical fertilizer overuse negatively influences soil microbial ecology and terrestrial and aquatic ecosystem function 
(Robertson \& Vitousek, 2009). Therefore, minimal chemical fertilizer inputs for maintaining healthy soil and high crop productivity are urgently needed for commercial sugarcane production in China.

Intercropping, which involves growing two or more crop species simultaneously in the same field, is an ancient cropping system that is practiced all around the world (Solanki et al., 2016). Intercropping contributes to the ecofunctional and sustainable intensification of crop production (Raseduzzaman \& Jensen, 2017) and is considered an efficient way to achieve agriculture sustainability (Vandermeer, 2011). At present, intercropping is more common in developing countries than developed countries and is practiced mostly by small and subsistence farmers (Sileshi et al., 2012). Intercropping enables agricultural intensification, which delivers higher yields per unit area and increases resource use efficiency compared with monoculture crops (Hauggaard-Nielsen et al., 2008). In particular, the application rates of synthetic nitrogen fertilizer can be reduced by legume intercropping owing to its capacity for biological nitrogen fixation. Moreover, intercropping promotes biodiversity in cropping systems and causes them to be more resilient when faced with environmental stresses, diseases and pests (Frison et al., 2011; Brooker et al., 2014). However, not all intercropping systems deliver yield benefits or other positive outcomes. For example, some cereal-legume intercropping methods produce lower biomass and nitrate accumulations in soil than that of monoculture crops (Li et al., 2001; Luo et al., 2016). Recently, some studies have compared intercropping to monocultures by focusing mainly on weed control, management factors, intercrop productivity, and resource use efficiency (Weerarathne et al., 2017; Yu et al., 2015, 2016; Pelzer et al., 2014). However, little is known about the effects of different intercrops on soil quality, particularly soil biology and related processes in China.

Soil quality depends on a large number of physical, chemical, biological, biochemical and microbiological parameters (Chaer et al., 2009). In particular, the latter two are the most sensitive indicators and respond rapidly to changes (Bastida et al., 2008). Soil enzyme activity is capable of reflecting ecosystem processes (Doran \& Zeiss, 2000). In addition to enzymatic activity, soil microbial biomass carbon (MBC), microbial biomass nitrogen (MBN) and microbial biomass phosphorus (MBP) are also used to monitor soil quality (Pandey et al., 2014). Soil microorganisms play an important role in soil biogeochemical processes, such as nitrogen, phosphorus and other element cycles (Urbanová et al., 2015). It is now recognized that soil microbial community composition and diversity determine soil health and crop productivity to a great extent (Mangan et al., 2010).

Therefore, in the present study, we investigated soil fertility and soil bacterial diversity under different sugarcane-legume intercropping systems, which are an important but overlooked aspect of the very promising crop diversification systems in China.

\section{Method}

\subsection{Field Site Description and Experimental Designs}

Field experiments were carried out in the 2016-17 and 2017-18 crop seasons at the experimental farm of the Guangxi South Sub-tropical Agricultural Science Research Institute, Longzhou (106 47'34"E and 22 $\left.12^{\circ} 42^{\prime \prime} \mathrm{N}\right)$. The experimental site locates in southern subtropical monsoon climate zone, which is rich in sunshine and abundant rainfall. And it is slightly cold in winter and spring, hot and rainy in summer, warm and cool in autumn, distinct dry and wet seasons. The average annual temperature is around $22{ }^{\circ} \mathrm{C}$, and the annual precipitation is around $1273.6 \mathrm{~mm}$. Experiments were conducted using a randomized block design with three replications to study the performances of a sugarcane monoculture as control and sugarcane intercropping treatments with soybean [Glycine max (Linn.) Merr.], mung bean [(Vigna radiata (Linn.) Wilczek], or peanut (Arachis hypogaea Linn.) with a 2:2 design (two rows of soybean, mung bean or peanut planted between each sugarcane row). Total of 4 treatments, each treatment set up 3 replications, a total of 12 plots, each plot 5 rows, row length 7 m, sugarcane cultivation row spacing $1.8 \mathrm{~m}$, plot area $63 \mathrm{~m}^{2}$. The experimental land was plowed and harrowed using a tractor to open rows and then planted. Soya beans (variety name: Gui Chun 10), mung beans (variety name: Medium Green 8) and peanuts (variety name: Gui Hua 1026) were planted between the sugarcane (variety name: ROC 22) rows. All intercropping treatments were all managed in the same conventional method.

\subsection{Soil Sampling and Soil Biological Properties Analysis}

Soil samples were collected in July 2018 from 12 plots that represented all the treatments in the intercropping experiments. To collect soil samples, the auger was sprayed with $75 \%$ ethanol for disinfection firstly, and then soil samples were collected by sterilized auger with the same depth of $40 \mathrm{~cm}$ in each treatment plot. From each plot, soil samples were collected from 12 random sites and mixed well. These soil samples were collected in sterile plastic bags and placed on ice in an ice box. The samples were immediately transferred to the laboratory, where they were sieved through a $2-\mathrm{mm}$ mesh stainless steel sieve, and then stored in a refrigerator at $4{ }^{\circ} \mathrm{C}$ for immediate analysis or were stored at $-80^{\circ} \mathrm{C}$ for later use. Meanwhile, portions of the soil samples were air dried 
for soil chemical analyses. The sample soils had an average $\mathrm{pH}$ of 6.2 , while the organic matter, total nitrogen, available phosphorus and potassium contents were $23.3 \mathrm{~g} \mathrm{~kg}^{-1}, 1.77 \mathrm{~g} \mathrm{~kg}^{-1}, 12.4 \mathrm{mg} \mathrm{kg}^{-1}$ and $66.1 \mathrm{mg} \mathrm{kg}^{-1}$, respectively.

\subsubsection{Soil Physical and Chemical Properties Analysis}

Soil pH was measured using a pH meter (soil water ratio 1:2.5) (Reijonen et al., 2016). Soil organic matter was determined by potassium dichromate-sulfate colorimetric method (Walkley, 1935). Total nitrogen was determined by the Kjeldahl method (Tsiknia et al., 2014). Available phosphorus, and available potassium were subjected to the double acid method and flame photometry respectively (Bao, 2013).

\subsubsection{Soil Microbial Numbers}

Microbial numbers were determined using the agar plate dilution method modified with cycloheximide $(100 \mu \mathrm{g}$ $\mathrm{L}^{-1}$ ) as described by Martin (1950). Rose Bengal-streptomycin agar medium and starch casein medium were used to determine the fungi and actinomycetes numbers in fresh soil samples as described by Miyashita (1997). The $\mathrm{pH}$ levels of the media were adjusted to 6.8 with $\mathrm{HCl}$ or $\mathrm{NaOH}$. Microbial counts were determined for 5 replicates.

\subsubsection{Soil Microbial Biomass}

The soil microbial biomass $\mathrm{N}(\mathrm{MBN})$ and soil microbial biomass $\mathrm{C}(\mathrm{MBC})$ contents were determined using the chloroform fumigation-extraction method as described by Brookes et al. (1985) and Vance et al. (1987). The contents of soil microbial biomass P (MBP) contents were determined by the phosphorus molybdenum blue colorimetric method (Powlson et al., 1987).

\subsubsection{Soil Enzyme Activities}

$\beta$-Glucosidase (EC.3.2.1.21) assays were based on $\rho$-nitrophenol ( $p$ NP) release after cleavage of a synthetic substrate (Hayano, 1973). In brief, the color of the released $\rho$-nitrophenol was measured at $400 \mathrm{~nm}$ using a spectrophotometer (UV-1700, Shimadzu, Japan). A standard curve was plotted using 0-80 $\mu \mathrm{g} \mathrm{mL}$ concentrations of $\rho$-nitrophenol. Enzyme activities are expressed as nmol $p \mathrm{NP}$ released per $\mathrm{g}$ dry soil per minute (nmol $p \mathrm{NP} \mathrm{g}^{-1} \mathrm{~min}^{-1}$ ).

Acid phosphatase activity in soils was estimated by measuring the amount of $\rho$ NP released after incubating the samples with $\rho$-nitrophenyl-phosphate (Alef et al., 1995). In a reaction tube, $0.25 \mathrm{~mL}$ of toluene, $4.0 \mathrm{~mL}$ of modified universal buffer (5x MUB, $\mathrm{pH}$ 6.0, which was made by dissolving $12.1 \mathrm{~g}$ of Tris, $11.6 \mathrm{~g}$ of maleic acid, $14.0 \mathrm{~g}$ of citric acid and $6.3 \mathrm{~g}$ of boric acid in $500 \mathrm{~mL}$ of $1 \mathrm{M} \mathrm{NaOH}$ to make a volume of $1 \mathrm{~L}$ ), and $1.0 \mathrm{~mL}$ $\rho$-nitrophenyl-phosphate $\left(15 \mathrm{mmol} \mathrm{L}\right.$ ) were added to $1.0 \mathrm{~g}$ of soil sample and incubated at $37^{\circ} \mathrm{C}$ for $1 \mathrm{~h}$. The reaction was terminated by adding $1.0 \mathrm{~mL}$ of $0.5 \mathrm{~mol} \mathrm{CaCl}_{2}$ and $4.0 \mathrm{~mL}$ of $0.5 \mathrm{~mol} \mathrm{NaOH}$ to the mixture prior to filtration. The absorbance of the released $\rho \mathrm{NP}$ was measured at $400 \mathrm{~nm}$ using a spectrophotometer (UV-1700, Shimadzu, Japan), and the phosphatase activity is expressed in $\mathrm{mg} \rho-\mathrm{NP} \mathrm{g}^{-1} \mathrm{~h}^{-1}$.

Aminopeptidase activity was measured using the method described by Pansombat et al. (1997) with $0.002 \mathrm{M}$ $\mathrm{N}$-benzoyl-Lxycarbonylglycyl L-phenylalanine (ZGP). The absorbance at a wavelength of $570 \mathrm{~nm}$ was measured using a spectrophotometer (UV-1700, Shimadzu, Japan). All analyses were conducted with 5 replicates.

\subsection{Analysis of Soil Microbial Diversity}

Microbial community genomic DNA was extracted from samples using the E.Z.N.A. ${ }^{\circledR}$ soil DNA Kit (Omega Bio-tek, Norcross, GA, U.S.) according to the manufacturer's instructions. The DNA extract was checked on a $1 \%$ agarose gel, and the DNA concentrations and purity were determined with a NanoDrop 2000 UV-vis spectrophotometer (Thermo Scientific, Wilmington, USA). PCR amplification and sequencing of the total DNA extracted from the rhizosphere soil samples were performed by Shanghai Majorbio Bio-pharm Technology Co., Ltd. (Shanghai, China), while PCR amplification was performed using an ABI GeneAmp 9700 instrument (ABI, USA), and the PCR products were recovered using $2 \%$ agar-gel electrophoresis. The products were purified by using an AxyPrep DNA Gel Extraction Kit (Axygen, USA) and quantified using a Quantus Fluorometer (Promega, USA). The purified amplicons were pooled in equimolar quantities and were paired-end sequenced $(2 \times 300)$ on the Illumina MiSeq platform (Illumina, San Diego, USA) according to the standard protocols of the Majorbio Bio-Pharm Technology Co. Ltd. (Shanghai, China). Raw reads were deposited in the NCBI Sequence Read Archive (SRA) database (Accession Number: SRP284471).

\subsection{Statistical Analyses}

The experimental data were analyzed using Excel 2019 and Statistical Product and Service Solutions (SPSS) Statistics 21, and the results are shown as means with their standard deviations (mean $\pm \mathrm{SD}$ ). Online data analysis 
was conducted using the free online platform of the Majorbio Cloud Platform (http://www.majorbio.com) of the Majorbio Bio-Pharm Technology Co. Ltd. (Shanghai, China).

\section{Results}

\subsection{Soil Enzyme Activities}

The activities of soil $\beta$-glucosidase in the treatments using sugarcane-soybean and sugarcane-mung bean intercropping were significantly higher than those in the monoculture and sugarcane/peanut intercropping treatment (Table 1). No significant difference in soil $\beta$-glucosidase activity was observed between sugarcane-peanut intercropping and the monoculture. The highest $\beta$-glucosidase activity was found in the sugarcane-mung bean system, which was significantly greater than that in sugarcane-soybean treatment (Table 1). Acid phosphatase activity showed nearly the same trend as that of $\beta$-glucosidase except that there were no significant differences between the sugarcane-soybean and sugarcane-mung bean intercropping treatments. Aminopeptidase activity was significantly different among all treatments, with the sugarcane-peanut system showing slightly lower activity than that of the monoculture (Table 1).

Table 1. Soil enzyme activities (nmol g-1 $\mathrm{min}^{-1}$ at $30{ }^{\circ} \mathrm{C}$ ) in the sugarcane monoculture and different sugarcane-legume intercropping systems

\begin{tabular}{llll}
\hline Treatments & $\beta$-Glucosidase & Aminopeptidase & Phosphatase \\
\hline Sugarcane-soybean & $1.21 \pm 0.21 \mathrm{~b}$ & $10.15 \pm 0.54 \mathrm{~b}$ & $1.58 \pm 0.09 \mathrm{a}$ \\
Sugarcane-mung bean & $1.39 \pm 0.41 \mathrm{a}$ & $11.32 \pm 0.27 \mathrm{a}$ & $1.62 \pm 0.14 \mathrm{a}$ \\
Sugarcane-peanut & $0.97 \pm 0.08 \mathrm{c}$ & $8.77 \pm 0.21 \mathrm{~d}$ & $1.15 \pm 0.09 \mathrm{~b}$ \\
Monoculture & $1.01 \pm 0.22 \mathrm{c}$ & $9.87 \pm 0.41 \mathrm{c}$ & $1.14 \pm 0.09 \mathrm{~b}$ \\
\hline
\end{tabular}

Note. All data are presented as means \pm SD (standard deviation). Different letters in the same column indicate significant differences among treatments at $P<0.05$.

\subsection{Soil Microbial Biomass}

As shown in Table 2, the soil microbial biomass carbon (MBC), nitrogen (MBN) and phosphorus (MBP) contents were highest in the sugarcane-mung bean intercropping treatments. All of these three parameters were significantly higher in the sugarcane-soybean and sugarcane-mung bean intercropping systems than those of the sugarcane-peanut and monoculture treatments. The soil microbial biomass $\mathrm{C}$ content in the sugarcane-peanut treatment was significantly lower than that in the monoculture, but the opposite trend was observed for MBP (Table 2). The soil microbial biomass $\mathrm{N}$ contents in the sugarcane-peanut and monoculture treatments remained similar with those of MBN.

Table 2. Soil microbial biomass carbon (MBC), nitrogen (MBN) and phosphorus (MBP) $\left(\mathrm{mg} \mathrm{kg}^{-1}\right)$ in the sugarcane monoculture and different sugarcane-legume intercropping systems

\begin{tabular}{llll}
\hline Treatments & MBC & MBN & MBP \\
\hline Sugarcane-soybean & $161.5 \pm 7.84 \mathrm{~b}$ & $14.8 \pm 0.41 \mathrm{~b}$ & $227.8 \pm 5.46 \mathrm{~b}$ \\
Sugarcane-mung bean & $184.2 \pm 6.55 \mathrm{a}$ & $18.7 \pm 0.89 \mathrm{a}$ & $255.6 \pm 9.63 \mathrm{a}$ \\
Sugarcane-peanut & $111.9 \pm 5.63 \mathrm{~d}$ & $13.4 \pm 0.56 \mathrm{c}$ & $199.3 \pm 4.53 \mathrm{c}$ \\
Monoculture & $137.7 \pm 9.05 \mathrm{c}$ & $13.5 \pm 0.36 \mathrm{c}$ & $180.4 \pm 3.47 \mathrm{~d}$ \\
\hline
\end{tabular}

Note. All data are presented as means \pm SD (standard deviation). Different letters in the same column indicate significant differences among treatments at $P<0.05$.

\subsection{Soil Cultivable Microorganisms}

The relative numbers of cultivable bacteria, fungi and actinomycetes in the soils of the sugarcane-soybean, sugarcane-mung bean and sugarcane-peanut treatments and the sugarcane monoculture followed a somewhat similar pattern, as the MBC, MBN and MBP contents (Table 3). In particular, the sugarcane-soybean and sugarcane-mung-bean systems were superior to the other two treatments. Notably, the abundances of cultivable fungi and actinomycetes in the sugarcane-peanut and sugarcane monoculture systems did not show any 
significant variations, but the cultivable bacterial population was lower in the sugarcane-peanut intercropped soil than those in the monoculture (Table 3).

Table 3. Soil enzyme activities $\left(\mathrm{nmol} \mathrm{g} \mathrm{g}^{-1} \mathrm{~min}^{-1}\right.$ at $30{ }^{\circ} \mathrm{C}$ ) in the sugarcane monoculture and different sugarcane-legume intercropping systems

\begin{tabular}{llll}
\hline Treatment & Bacteria $\left(10^{6} \mathrm{CFU} \cdot \mathrm{g}^{-1}\right)$ & Fungi $\left(10^{4} \mathrm{CFU} \cdot \mathrm{g}^{-1}\right)$ & Actinomycetes $\left(10^{6} \mathrm{CFU} \cdot \mathrm{g}^{-1}\right)$ \\
\hline Sugarcane-soybean & $24.31 \pm 0.16 \mathrm{~b}$ & $5.84 \pm 0.58 \mathrm{~b}$ & $24.87 \pm 0.66 \mathrm{~b}$ \\
Sugarcane-mung bean & $29.92 \pm 0.22 \mathrm{a}$ & $6.14 \pm 0.67 \mathrm{a}$ & $27.75 \pm 1.22 \mathrm{a}$ \\
Sugarcane-peanut & $15.96 \pm 0.47 \mathrm{~d}$ & $4.24 \pm 0.64 \mathrm{c}$ & $15.89 \pm 0.74 \mathrm{c}$ \\
Monoculture (CK) & $18.54 \pm 0.57 \mathrm{c}$ & $4.49 \pm 0.23 \mathrm{c}$ & $15.54 \pm 0.85 \mathrm{c}$ \\
\hline
\end{tabular}

Note. All data are presented as means \pm SD (standard deviation). Different letters in the same column indicate significant differences among treatments at $P<0.05$.

\subsection{Soil Bacterial Diversity and Richness}

The Shannon index, which describes bacterial diversity, was highest for the soil from sugarcane-mung bean intercropping compared to the other three treatments (Table 4). For the other parameters described so far, the bacterial diversities of the soils from the sugarcane-soybean and sugarcane-mung bean intercrops were significantly higher than those of the sugarcane-peanut and sugarcane monoculture systems. In addition, the bacterial richness indices, such as Ace and Chao1, showed that sugarcane-mung bean and sugarcane-soybean did not differ in bacterial richness but were richer than those of other treatments. Our data indicate increased bacterial abundance in the sugarcane-peanut treatment compared to the sugarcane monoculture (Table 4).

Table 4. Richness and diversity at a similarity level of $97 \%$ for soil bacteria in the sugarcane monoculture and different sugarcane-legume intercropping systems

\begin{tabular}{lllll}
\hline Treatments & Shannon index & Ace index & Chao1 index & Coverage \\
\hline Sugarcane-soybean & $6.15 \pm 0.07 \mathrm{ab}$ & $2395.2 \pm 20.2 \mathrm{a}$ & $2411.4 \pm 36.0 \mathrm{a}$ & 0.98 \\
Sugarcane-mung bean & $6.34 \pm 0.02 \mathrm{a}$ & $2429.6 \pm 114.4 \mathrm{a}$ & $2453.2 \pm 95.7 \mathrm{a}$ & 0.98 \\
Sugarcane-peanut & $5.92 \pm 0.23 \mathrm{~b}$ & $1860.2 \pm 83.0 \mathrm{~b}$ & $1892.3 \pm 52.7 \mathrm{~b}$ & 0.99 \\
Monoculture & $5.95 \pm 0.04 \mathrm{~b}$ & $1639.6 \pm 22.5 \mathrm{c}$ & $1683.9 \pm 17.3 \mathrm{c}$ & 0.99 \\
\hline
\end{tabular}

Note. All data are presented as means \pm SD (standard deviation). Different letters in the same column indicate significant differences among treatments at $P<0.05$.

\subsection{Compositions of Soil Bacterial Communities in the Sugarcane Monoculture and Sugarcane-Legume Intercropping Systems}

At the phylum level, the dominant soil bacteria (i.e., relative abundances greater than 1\%) in fields of sugarcane intercropping or monoculture systems can be divided into ten (sugarcane-soybean and sugarcane-mung bean intercrops), nine (sugarcane monoculture) and eight (sugarcane-peanut intercrop) phyla (Figure 1). In the sugarcane monoculture, the proportions of the dominant bacterial groups (ordered from large to small) were Actinobacteria, Proteobacteria, Chloroflexi, Acidobacteria, Firmicutes, Planctomycetes, Bacteroidetes, Gemmatimonadetes and the others group. Their relative proportions were $25.05 \%, 22.20 \%, 21.53 \%, 11.49 \%$, $11.45 \%, 2.68 \%, 1.28 \%, 1.06 \%$, and $1.95 \%$, respectively. In contrast, the relative abundances (shown in parentheses) of the dominant bacteria in the sugarcane-soybean treatment (Figure 1A) were Proteobacteria (25.99\%), Actinobacteria (23.30\%), Chloroflexi (17.74\%), Firmicutes (14.72\%), Acidobacteria (9.59\%), Planctomycetes (2.04\%), Gemmatimonadetes (1.85\%), Bacteroidetes (1.56\%), Nitrospirae (1.05\%) and others $(1.27 \%)$. In the sugarcane-mung bean treatment (Figure 1B), the compositions and abundances (shown in parentheses) of the dominant bacteria were Actinobacteria (24.89\%), Proteobacteria (23.20\%), Chloroflexi (20.81\%), Acidobacteria (11.59\%), Firmicutes (9.00\%), Planctomycetes (2.76\%), Bacteroidetes (1.63\%), Saccharibacteria (1.59\%), Gemmatimonadetes (1.58\%) and others $(2.46 \%)$. In the sugarcane-peanut treatment, Actinobacteria (23.53\%), Proteobacteria (21.12\%), Chloroflexi (22.49\%), Firmicutes (14.21\%), Acidobacteria $(10.67 \%)$, Planctomycetes $(3.11 \%)$, and Saccharibacteria $(1.40 \%)$ dominated, and their relative proportions are shown in parentheses (Figure 1C). 
Community analysis pie chart at the Phylum level : Sugarcane/soybean (A)

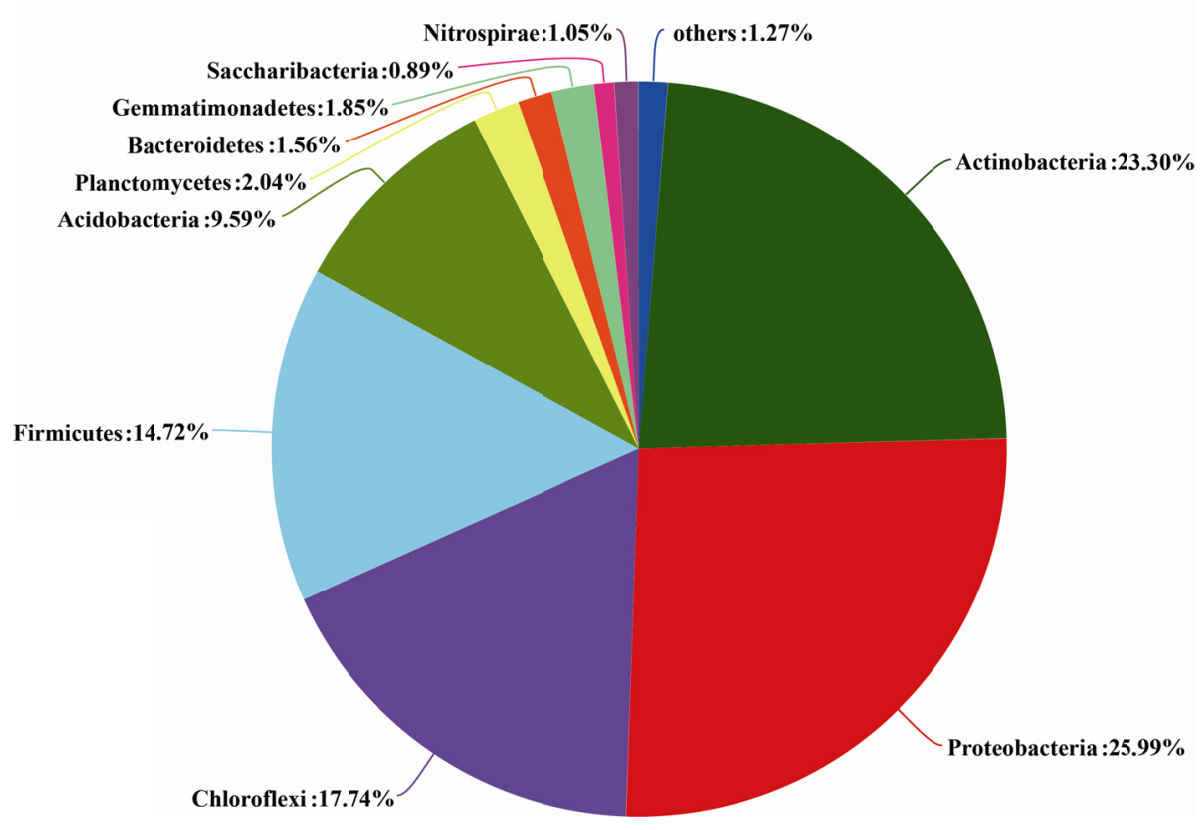

Community analysis pie chart at the Phylum level : Sugarcane/mung bean (B)

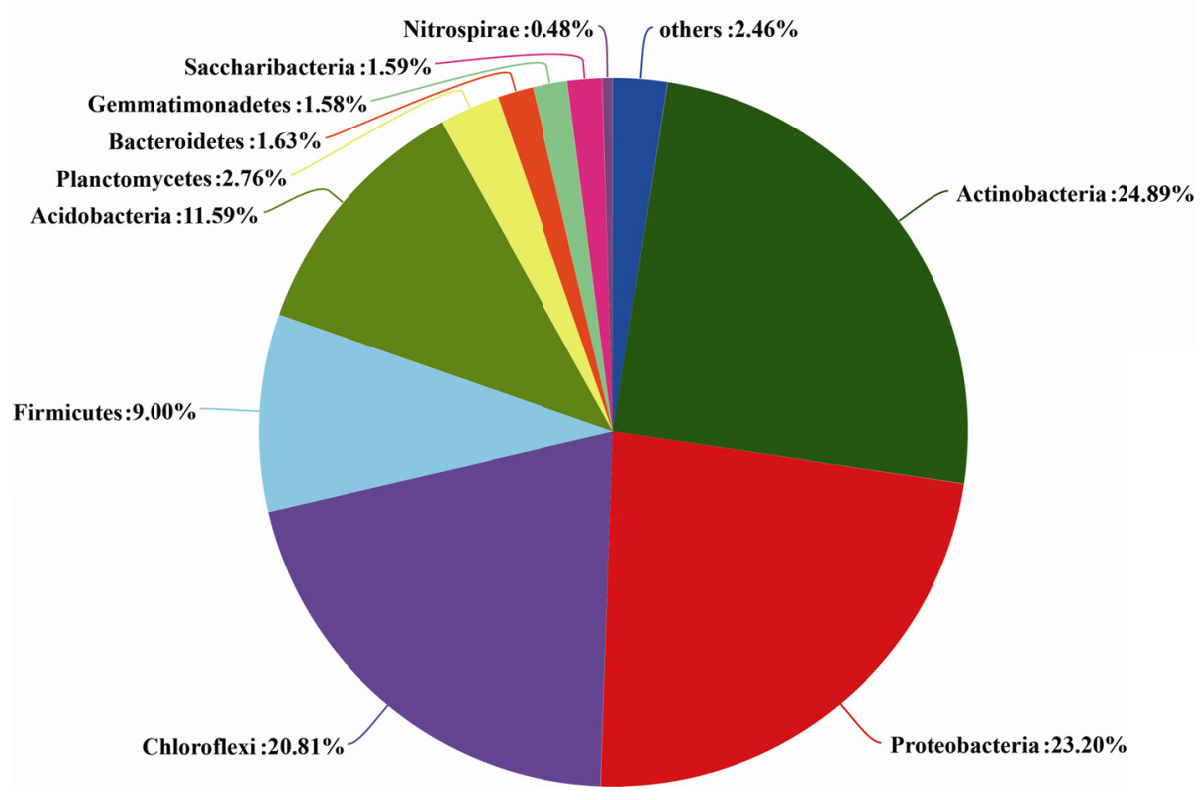


Community analysis pie part at the Phylum level : Sugarcane/peanut (C)

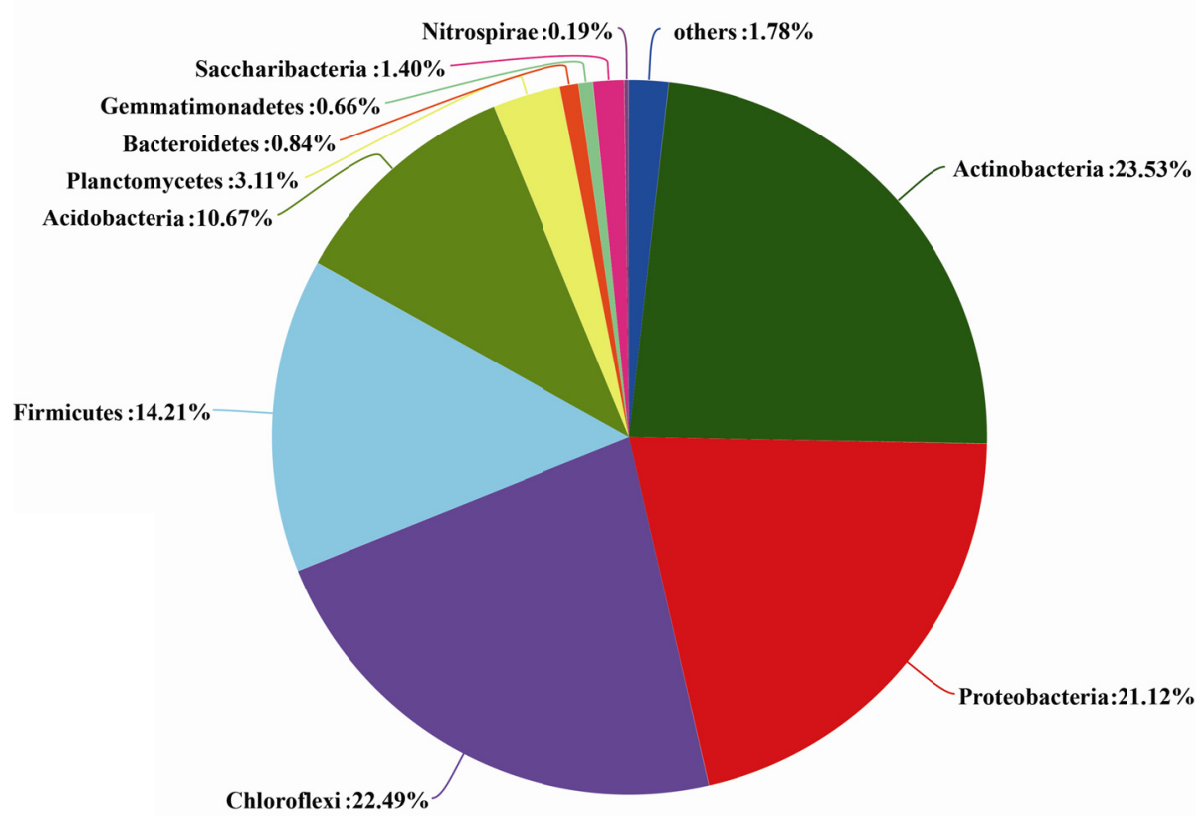

Community analysis pie part at the Phylum level : Sugarcane (CK)

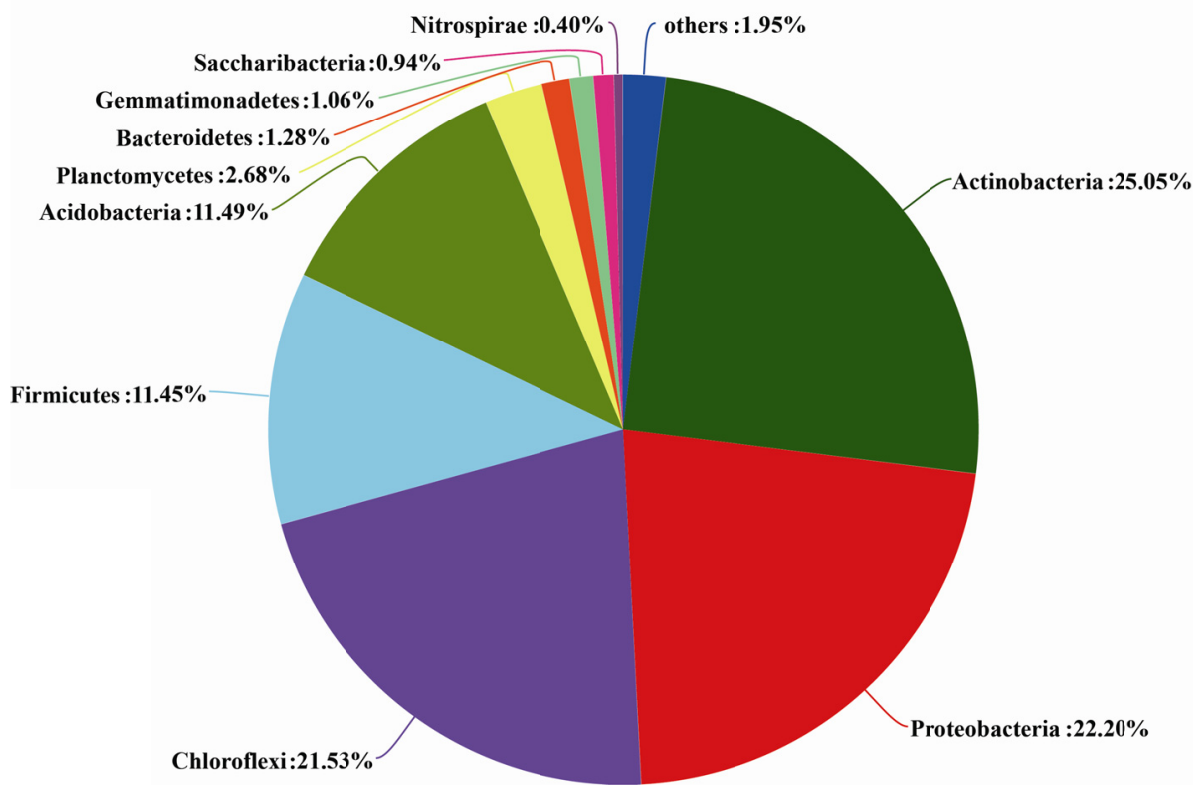

Figure 1. Compositions of soil bacterial communities at the phylum level among the sugarcane monoculture and sugarcane-legume intercrops

Note. A: sugarcane intercropped with soybean, B: sugarcane intercropped with mung bean, C: sugarcane intercropped with peanut, and CK: sugarcane monoculture. 


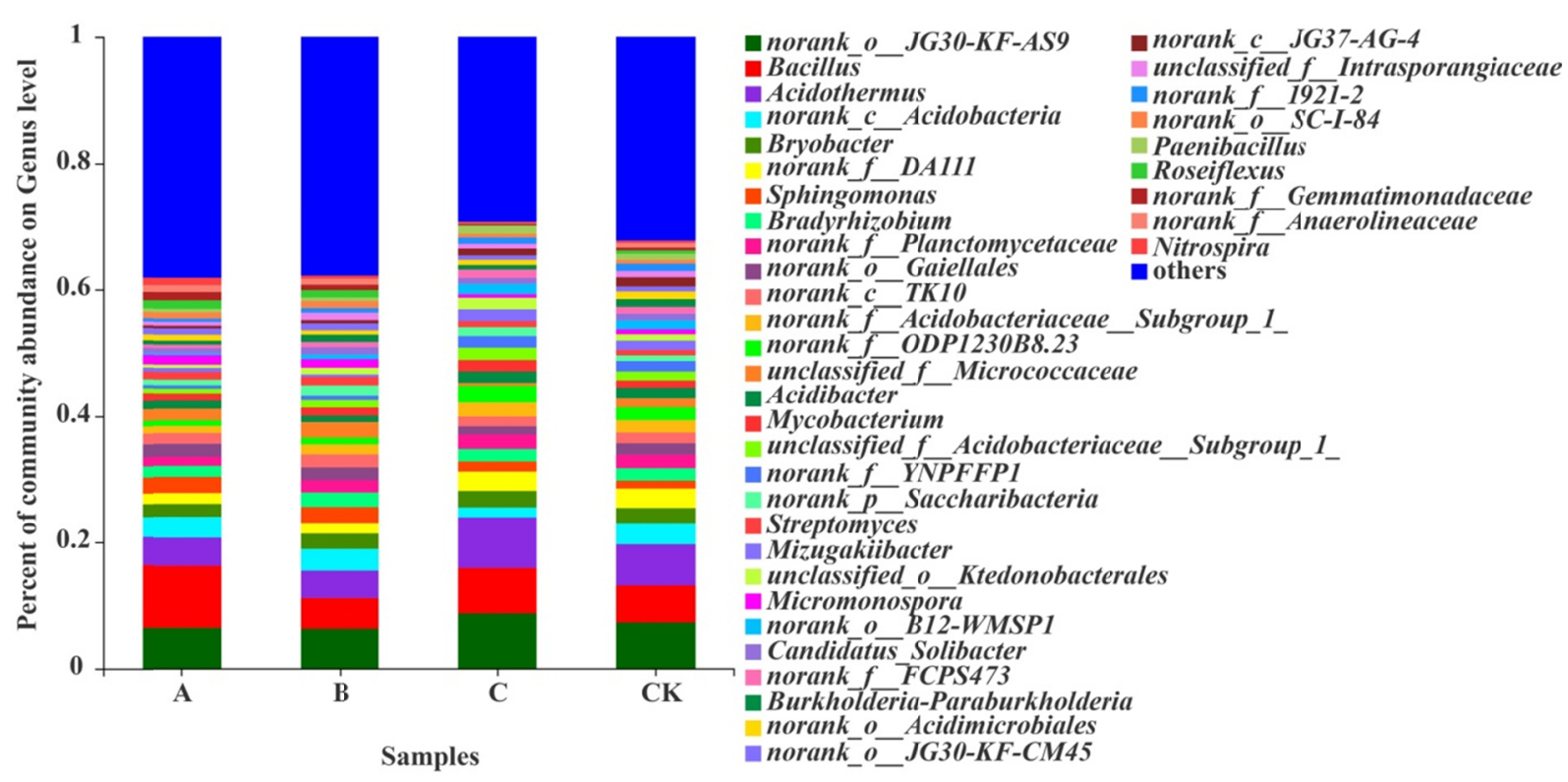

Figure 2. Compositions of soil bacterial communities at the genus level among the sugarcane monoculture and sugarcane-legume intercrops

Note. A: sugarcane intercropped with soybean, B: sugarcane intercropped with mung bean, C: sugarcane intercropped with peanut, and CK: sugarcane monoculture.

Figure 2 shows that the dominant soil bacteria in sugarcane fields under the four treatments were consisted of over 39 genera. Table 5 lists the compositions and relative proportions of the dominant soil bacterial genera that were identified in this study. The numbers of identified bacterial genera in the A, B, C and CK treatments were 24, 28, 26 and 27, respectively.

All of these results show that the intercropping treatments not only changed the proportions of dominant soil bacteria but also altered the compositions and structures of soil bacterial communities (Table 5). 
Table 5. Compositions of dominant soil bacterial communities at the genus level and their relative abundances (\%) in soils from the sugarcane monoculture and sugarcane-legume intercrops

\begin{tabular}{|c|c|c|c|c|}
\hline Genus & $\mathrm{A}$ & $\mathrm{B}$ & $\mathrm{C}$ & $\mathrm{CK}$ \\
\hline norank_o_JG30-KF-AS9 & 6.40 & 6.26 & 8.71 & 7.26 \\
\hline Bacillus & 9.96 & 4.87 & 7.31 & 5.97 \\
\hline Acidothermus & 4.48 & 4.47 & 7.94 & 6.55 \\
\hline norank_c_Acidobacteria & 3.21 & 3.44 & 1.58 & 3.25 \\
\hline Bryobacter & 2.05 & 2.45 & 2.56 & 2.41 \\
\hline norank $f \_D A 111$ & 1.66 & 1.57 & 3.07 & 3.02 \\
\hline Sphingomonas & 2.58 & 2.54 & 1.61 & 1.28 \\
\hline Bradyrhizobium & 1.74 & 2.25 & 1.95 & 1.96 \\
\hline norank $f \_$Planctomycetaceae & 1.44 & 1.97 & 2.30 & 2.13 \\
\hline norank_o__Gaiellales & 2.05 & 2.02 & 1.30 & 1.81 \\
\hline norank_c_tTK10 & 1.71 & 2.05 & 1.53 & 1.72 \\
\hline norank_f_Acidobacteriaceae_Subgroup_1_ & 1.13 & 1.59 & 2.26 & 1.95 \\
\hline norank_f_ODP1230B8.23 & - & 1.06 & 2.68 & 2.06 \\
\hline unclassified_f__Micrococcaceae & 1.84 & 2.47 & - & 1.40 \\
\hline Acidibacter & 1.29 & 1.02 & 1.82 & 1.74 \\
\hline Mycobacterium & 1.19 & 1.30 & 1.82 & 1.15 \\
\hline unclassified_f_Acidobacteriaceae_Subgroup_1_ & - & 1.16 & 1.95 & 1.42 \\
\hline norank $f \_Y N P F F P 1$ & - & - & 1.84 & 1.65 \\
\hline norank_p_Saccharibacteria & - & 1.57 & 1.41 & - \\
\hline Streptomyces & 1.26 & 1.37 & - & - \\
\hline Mizugakiibacter & - & - & 1.87 & 1.47 \\
\hline unclassified_o_Ktedonobacterales & - & 1.06 & 1.74 & - \\
\hline Micromonospora & 1.51 & 1.35 & - & - \\
\hline norank_o_B12-WMSP1 & - & - & 1.64 & 1.39 \\
\hline Candidatus_Solibacter & - & 1.21 & - & 1.06 \\
\hline norank $f \_F C P S 473$ & - & - & 1.32 & 1.07 \\
\hline Burkholderia-Paraburkholderia & - & 1.17 & - & 1.17 \\
\hline norank_o_Acidimicrobiales & - & - & - & 1.21 \\
\hline norank_o_JG30-KF-CM45 & 1.01 & 1.11 & - & - \\
\hline norank_c_JG37-AG-4 & - & - & 1.09 & 1.47 \\
\hline unclassified_f_Intrasporangiaceae & - & 1.16 & - & - \\
\hline norank $f \_1921-2$ & - & - & 1.02 & 1.15 \\
\hline norank_o_SC-I-84 & 1.00 & 1.08 & - & - \\
\hline Paenibacillus & - & - & 1.26 & - \\
\hline Roseiflexus & 1.30 & 1.17 & - & - \\
\hline norank_f_Gemmatimonadaceae & 1.32 & - & - & - \\
\hline norank_f_Anaerolineaceae & 1.07 & - & - & - \\
\hline Nitrospira & 1.19 & - & - & - \\
\hline others & 38.13 & 37.8 & 29.29 & 32.26 \\
\hline
\end{tabular}

Note. A: sugarcane intercropped with soybean, B: sugarcane intercropped with mung bean, C: sugarcane intercropped with peanut, and CK: sugarcane monoculture.

The total numbers of bacteria in the sugarcane-soybean, sugarcane-mung bean, sugarcane-peanut and monoculture soil samples were 505, 492, 403 and 464, respectively (Figure 3-1: A, B, C, and CK). Additionally, the numbers of unique bacteria in these treatments (in the same order) were 28, 22, 0 and 2, respectively (Figure 3-1A, B, C, CK). The total numbers of bacteria at the operational taxonomic units (OTUs) level in the sugarcane-soybean sugarcane-mung bean, sugarcane-peanut (C) and sugarcane monoculture treatments were 2,609, 2,553, 1,910 and 2,358, respectively (Figure 3-2: A, B, C, CK). The unique bacteria numbers in these respective treatments were 214, 118, 23 and 49 (Figure 3-2: A, B, C, CK). These results indicate that the soil 
bacterial community structures of sugarcane soils can be significantly altered by legume intercropping, particularly with soybean and mung bean.
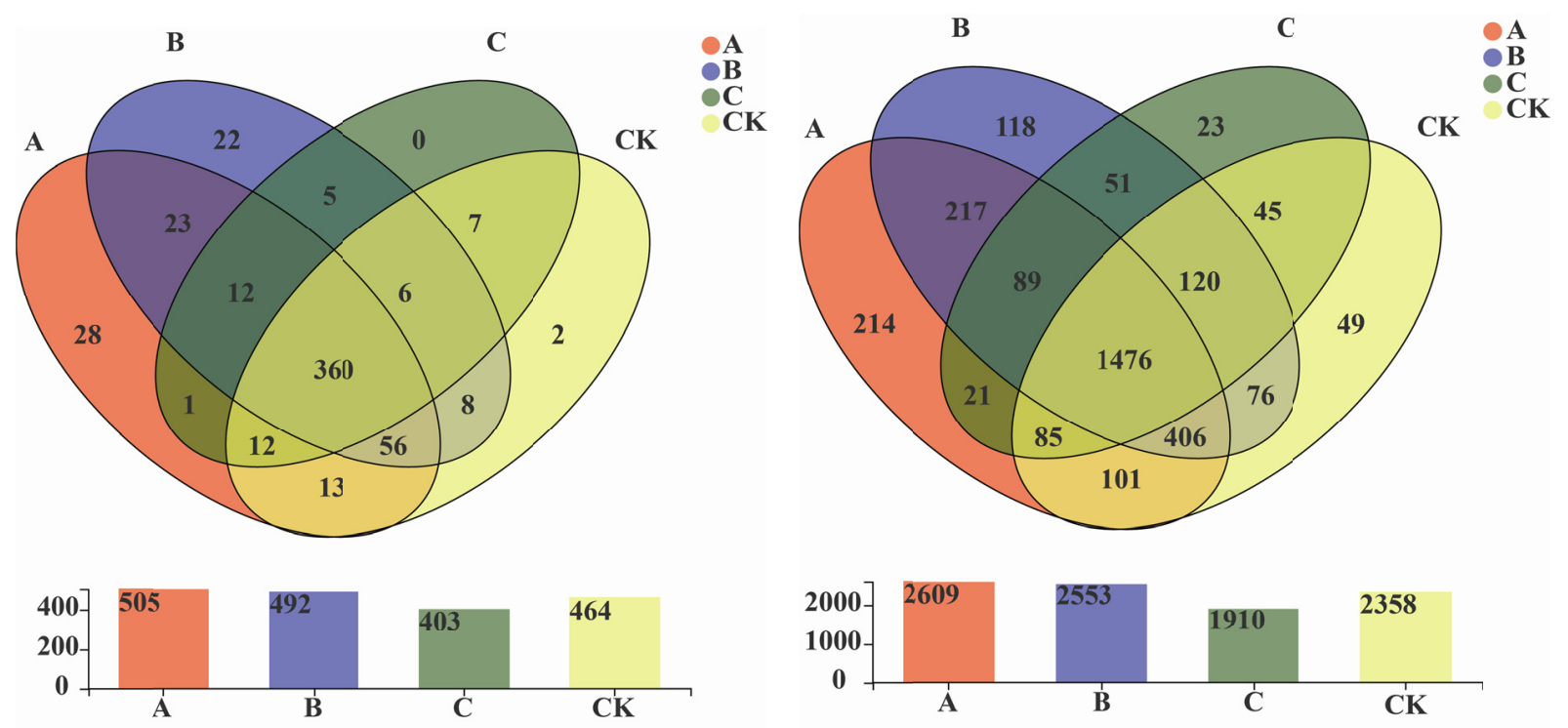

3-1

3-2

Figure 3. Venn analyses of soil bacteria for the four intercropping treatments at the genus (3-1) and OTU (3-2) levels

Note. A: sugarcane intercropped with soybean, B: sugarcane intercropped with mung bean, C: sugarcane intercropped with peanut, and CK: sugarcane monoculture.

\section{Discussion}

Previous studies have shown that intercropping is more beneficial to soil nutrient enrichment, plant nutrient acquisition and productivity than the corresponding monocultures. For example, researchers in China and sub-Saharan Africa have observed better crop yields and resource use even under adverse production conditions by using cereal-legume intercropping than monocultures (Kumar et al., 1998; Zhang \& Li, 2003; Mucheru-Muna et al., 2010; Wang et al., 2014). Despite these outcomes and the fact that legumes are known to contribute plant available nitrogen and boost yields and soil health, a mechanistic understanding of the intercropping-dependent improvement of soil health and crop yield remains poorly understood.

As mentioned before, low soil fertility is a critical limiting factor for cane yields and quality in China (Zeng et al., 2015). Soil acidification and all accompanying soil biotic and abiotic constraints for sugarcane crop improvement are widespread in many sugar-producing regions in China. In this context, legume intercropping with sugarcane appears to be a very desirable crop management strategy for reversing soil degradation and improving soil fertility and crop productivity, as has been observed for other broad acre crops (Zhang \& Li, 2003; Mucheru-Muna et al., 2010; Wang et al., 2014). Collectively, the results obtained in this study also support this assertion. For instance, soil microbial biomass is an important indicator of soil quality, soil fertility and crop productivity (Powlson et al., 1987). The greater the microbial biomass in soil, the greater the capacity of the soil to provide plant nutrients by mineralization of organic nutrients (Dwivedi \& Soni, 2011). Soil microbial biomass carbon promotes the formation of new humus and increases the soil total carbon content (Doran et al., 1996). Similarly, soil microbial biomass nitrogen reflects the availability of soil nitrogen to crops and plays an important role in soil nitrogen turnover and supply (Doran et al., 1996). Additionally, turnover of soil microbial biomass phosphorus, although it is not directly available to plants, releases inorganic phosphorus, which is very important for plant growth (Khan \& Joergensen, 2009). In this study, soil microbial biomass carbon, nitrogen and phosphorous were significantly higher in the sugarcane-mung bean and sugarcane-soybean intercropping treatments than in sugarcane-peanut treatments and sugarcane monoculture. These results suggest that soil 
microbial biomass in sugarcane fields can be improved considerably by intercropping with soybean, mung bean or, with a much reduced effect, peanut.

Soil enzymes are produced by microorganisms, other soil organisms and plant roots, and they have key biochemical functions, such as decomposing organic matter in the soil system (Ellert et al., 1997), and thereby release nutrients that are readily available for crop uptake. Soil enzymes also play an important role in facilitating microbial processes in the soil that stabilize soil structure, balance soil microbial ecology and drive nutrient cycling (Dick et al., 1994). In our study, the activities of soil $\beta$-glucosidase, aminopeptidase and acid phosphatase in sugarcane-soybean and sugarcane-mung bean intercropping systems were significantly higher than in sugarcane monocultures. This finding parallels the soil microbial biomass levels observed in our study, which indicate a significant contribution to nutrient cycling that is facilitated by increased levels of soil microflora in legume-intercropped sugarcane crops. Intercropping with soybean or mung bean thus significantly accelerates soil carbon, nitrogen and phosphorus cycles in sugarcane fields and promotes soil fertility and healthy soil ecology, which in turn, result in better crop performance

Soil microbial populations and their compositions are closely related to soil quality, which make them an ideal indicator of soil health (Brookes, 1995; Zhang et al., 2014). In our study, we found that the soil microbial population in sugarcane monocultures can be significantly improved by intercropping with soybean and mung bean but not as effectively with peanut. High-throughput sequencing of microbial populations revealed that the dominant bacteria at the phylum level represented eight phyla in sugarcane monocultures, e.g., Actinobacteria, Proteobacteria, Chloroflexi, Acidobacteria, Firmicutes, Planctomycetes, Bacteroidetes, and Gemmatimonadetes groups. In addition to these eight bacterial phyla in sugarcane monoculture fields, sugarcane-soybean soils were additionally enriched with Nitrospirae, while Saccharibacteria formed another dominant phylum in sugarcane-mung bean intercropped soils. Additionally, it is noteworthy that Saccharibacteria was also enriched in sugarcane-peanut intercropped fields. In addition to the new added dominant phyla, the orders of the dominant bacteria, based on their abundance levels, were also changed in intercropped soils. For instance, Proteobacteria was the third dominant phylum in sugarcane-peanut treatments but was first and second most abundant in sugarcane-soybean and sugarcane-mung bean systems, respectively. Generally, Proteobacteria are considered to be copiotrophic microorganisms, which thrive under conditions of high nutrient availability (Chen et al., 2016). These results suggest that legume intercropping promotes nutrient-tolerant soil bacterial community structures in sugarcane fields and thus positively impacts soil fertility. As the microbial community structures in rhizospheres can be changed by one or synergistically by both plant species (Yang et al., 2016; Song et al., 2007a, 2007b), we found significant variations in bacterial community compositions and abundances in intercropped soils compared to monoculture treatments. Collectively, our data suggest that intercropping systems, such as sugarcane-soybean and sugarcane-mung bean, are beneficial for improving soil biology and ecology, soil structure and soil fertility and lead to superior sustainable sugarcane agriculture. It is very likely that sugarcane-legume intercropping will also help meet the increasing demand for agricultural intensification and diversification without compromising the environmental obligations and economic outcomes of sugarcane agriculture.

\section{Conclusion}

In this study, a field experiment was carried out to elucidate the effects of intercropping sugarcane with different legumes on soil biological properties, soil bacterial diversities and community structures. The conclusions are as follows: The biological indicators of soil fertility in sugarcane fields, such as the activities of soil cultivable microorganisms (e.g., bacteria, fungi and actinomycetes), soil enzymes (e.g., $\beta$-Glucosidase, acid phosphatase, and aminopeptidase) and microbial biomass carbon, nitrogen, phosphorus, were all significantly improved by intercropping sugarcane with soybean and mung bean. Soil bacterial diversity and richness in sugarcane fields were also significantly enhanced by sugarcane intercropping with soybean and mung bean. By intercropping, new bacterial phyla, such as Nitrospirae or Saccharibacteria, became the dominant groups in intercropped soils. Proteobacteria, which thrives under conditions of high nutrient availability, became the most and second-most dominant bacterial group in sugarcane-soybean and sugarcane-mung bean systems. Sugarcane-mung bean intercropping showed the greatest effects for improving soil fertility and soil health among the cropping systems studied in this work.

\section{Acknowledgments}

This work was supported by National Natural Science Foundation of China (31760368), State Key Laboratory of Conservation and Utilization of Subtropical Agro-bioresources open fund (OSKL201506), Guangxi Key Laboratory of Sugarcane Genetic Improvement open fund (16-K-04-01), National Key R\&D Program of China (2018YFD0201100, 2018YFD0201103) and National technical position of sugar industry (Ratoon cultivation of 
sugarcane, 2017-2020, CARS-170206). The authors are also thankful to Dr. Prakash Lakshmanan [Principal Scientist, Sugarcane Research Australia (SRA), Australia] for his valuable comments and suggestions.

\section{References}

Alef, K., Nannipieri, P., \& Trazar-Cepeda, C. (1995). Phosphatase activity. In K. Alef \& P. Nannipieri (Eds.), Methods in Applied Soil Microbiology and Biochemistry (pp. 335-3344). London: Academic Press.

Bao, S. D. (2013). Soil and Agricultural Chemistry Analysis (3rd ed.). Beijing: China Agriculture Press.

Bastida, F., Kandeler, E., Moreno, J. L., Ros, M., García, C., \& Hernández, T. (2008). Application of fresh and composted organic wastes modifies structure, size and activity of soil microbial community under semiarid climate. Applied Soil Ecology, 40(2), 318-329. https://doi.org/10.1016/j.apsoil.2008.05.007

Brooker, R. W., Bennett, A. E., Cong, W. F., Daniell, T. J., George, T. S., Hallett, P. D., \& White, P. J. (2014). Improving intercropping: a synthesis of research in agronomy, plant physiology and ecology. New Phytologist, 206(1), 107-117. https://doi.org/10.1111/nph.13132

Brookes, P. (1995). The use of microbial parameters in monitoring soil pollution by heavy metals. Biology and Fertility of Soils, 19, 269-279. https://doi.org/10.1007/BF00336094

Brookes, P. C., Landman, A., Pruden, G., \& Jenkinson, D. S. (1985). Chloroform fumigation and the release of soil nitrogen: A rapid direct extraction method to measure microbial biomass nitrogen in soil. Soil Biology and Biochemistry, 17(6), 837-842. https://doi.org/10.1016/0038-0717(85)90144-0

Chaer, G., Fernandes, M., Myrold, D., \& Bottomley, P. (2009). Comparative Resistance and Resilience of Soil Microbial Communities and Enzyme Activities in Adjacent Native Forest and Agricultural Soils. Microbial Ecology, 58(2), 414-424. https://doi.org/10.1007/s00248-009-9508-X

Chandel, A. K., da Silva, S. S., Carvalho, W., \& Singh, O. V. (2011). Sugarcane bagasse and leaves: Foreseeable biomass of biofuel and bio-products. Journal of Chemical Technology \& Biotechnology, 87(1), 11-20. https://doi.org/10.1002/jctb.2742

Chen, L., Brookes, P. C., Xu, J., Zhang, J., Zhang, C., Zhou, X., \& Luo, Y. (2016). Structural and functional differentiation of the root-associated bacterial microbiomes of perennial rye grass. Soil Biology and Biochemistry, 98, 1-10. https://doi.org/10.1016/j.soilbio.2016.04.004

Dick, R. P., Sandor, J. A., \& Eash, N. S. (1994). Soil enzyme activities after 1500 years of terrace agriculture in the Colca Valley, Peru. Agriculture, Ecosystems \& Environment, 50(2), 123-131. https://doi.org/10.1016/ 0167-8809(94)90131-7

Doran, J. W., \& Zeiss, M. R. (2000). Soil health and sustainability: Managing the biotic component of soil quality. Applied Soil Ecology, 15(1), 3-11. https://doi.org/10.1016/s0929-1393(00)00067-6

Doran, J. W., Jones, A. J., Rice, C. W., Moorman, T. B., \& Beare, M. (1996). Role of Microbial Biomass Carbon and Nitrogen in Soil Quality. SSSA Special Publication, 49, 203-215. https://doi.org/10.2136/ sssaspecpub49.c12

Dwivedi, V., \& Soni, P. (2011). A review on the role of soil microbial biomass in eco-restoration of degraded ecosystem with special reference to mining areas. Journal of Applied and Natural Science, 3(1), 151-158. https://doi.org/10.31018/jans.v3i1.173

Ellert, B. H., Clapperton, M. J., \& Anderson, D. W. (1997). Chapter 5 An ecosystem perspective of soil quality. Developments in Soil Science, 25, 115-141. https://doi.org/10.1016/s0166-2481(97)80032-3

Frison, E. A., Cherfas, J., \& Hodgkin, T. (2011). Agricultural Biodiversity Is Essential for a Sustainable Improvement in Food and Nutrition Security. Sustainability, 3(1), 238-253. https://oi.org/10.3390/ su3010238

Hauggaard-Nielsen, H., Jørnsgaard, B., Kinane, J., \& Jensen, E. S. (2008). Grain legume-cereal intercropping: The practical application of diversity, competition and facilitation in arable and organic cropping systems. Renewable Agriculture and Food Systems, 23(01), 3-12. https://doi.org/10.1017/s1742170507002025

Hayano, K. (1973). A method for the determination of $\beta$-glucosidase activity in soil. Soil Science and Plant Nutrition, 19(2), 103-108. https://doi.org/10.1080/00380768.1973.10432524

Khan, K. S., \& Joergensen, R. G. (2009). Changes in microbial biomass and P fractions in biogenic household waste compost amended with inorganic P fertilizers. Bioresource Technology, 100(1), 303-309. https://doi.org/10.1016/j.biortech.2008.06.002 
Kumar, B. M., Kumar, S. S., \& Fisher, R. F. (1998). Agroforestry Systems, 42(1), 81-89. https://doi.org/ 10.1023/a:1006199910985

Li, L., Sun, J., Zhang, F., Li, X., Yang, S., \& Rengel, Z. (2001). Wheat/maize or wheat/soybean strip intercropping. Field Crops Research, 71(2), 123-137. https://doi.org/10.1016/s0378-4290(01)00156-3

Li, Y. (2004). China: An emerging sugar super power. Sugar Tech, 6(4), 213-227. https://doi.org/ 10.1007/bf02942501

Li, Y. R., \& Yang, L. T. (2014). Sugarcane Agriculture and Sugar Industry in China. Sugar Tech, 17(1), 1-8. https://doi.org/10.1007/s12355-014-0342-1

Luo, S., Yu, L., Liu, Y., Zhang, Y., Yang, W., Li, Z., \& Wang, J. (2016). Effects of reduced nitrogen input on productivity and $\mathrm{N}_{2} \mathrm{O}$ emissions in a sugarcane/soybean intercropping system. European Journal of Agronomy, 81, 78-85. https://doi.org/10.1016/j.eja.2016.09.002

Mangan, S. A., Schnitzer, S. A., Herre, E. A., Mack, K. M. L., Valencia, M. C., Sanchez, E. I., \& Bever, J. D. (2010). Negative plant-soil feedback predicts tree-species relative abundance in a tropical forest. Nature, 466(7307), 752-755. https://doi.org/10.1038/nature09273

Martin, J. P. (1950). Use of acid, rose Bengal and streptomycin in the plate method for estimating soil fungi. Soil Science, 69(3), 215-232. https://doi.org/10.1097/00010694-195003000-00006

Miyashita, S. (1997). Methods of soil microbiology (pp. 55-61). Japan: Yokendo, Ltd.

Mucheru-Muna, M., Pypers, P., Mugendi, D., Kung’u, J., Mugwe, J., Merckx, R., \& Vanlauwe, B. (2010). A staggered maize-legume intercrop arrangement robustly increases crop yields and economic returns in the highlands of Central Kenya. Field Crops Research, 115(2), 132-139. https://doi.org/10.1016/j.fcr.2009. 10.013

Mucheru-Muna, M., Pypers, P., Mugendi, D., Kung’u, J., Mugwe, J., Merckx, R., \& Vanlauwe, B. (2010). A staggered maize-legume intercrop arrangement robustly increases crop yields and economic returns in the highlands of Central Kenya. Field Crops Research, 115(2), 132-139. https://doi.org/10.1016/j.fcr.2009. 10.013

Pandey, D., Agrawal, M., \& Bohra, J. S. (2014). Effects of conventional tillage and no tillage permutations on extracellular soil enzyme activities and microbial biomass under rice cultivation. Soil and Tillage Research, 136, 51-60. https://doi.org/10.1016/j.still.2013.09.013

Pansombat, K., Kanazawa, S., \& Horiguchi, T. (1997). Microbial ecology in tea soils. Soil Science and Plant Nutrition, 43(2), 431-438. https://doi.org/10.1080/00380768.1997.10414766

Pelzer E., Hombert N., Jeuffroy M. H., \& Makowski, D. (2014) Meta-Analysis of the Effect of Nitrogen Fertilization on Annual Cereal-Legume Intercrop Production. Agronomy Journal, 106(5), 1775. https://doi.org/10.2134/agronj13.0590

Powlson, D. S., Prookes, P. C., \& Christensen, B. T. (1987). Measurement of soil microbial biomass provides an early indication of changes in total soil organic matter due to straw incorporation. Soil Biology and Biochemistry, 19(2), 159-164. https://doi.org/10.1016/0038-0717(87)90076-9

Powlson, D. S., Prookes, P. C., \& Christensen, B. T. (1987). Measurement of soil microbial biomass provides an early indication of changes in total soil organic matter due to straw incorporation. Soil Biology and Biochemistry, 19(2), 159-164. https://doi.org/10.1016/0038-0717(87)90076-9

Raseduzzaman, M., \& Jensen, E. S. (2017). Does intercropping enhance yield stability in arable crop production? A meta-analysis. European Journal of Agronomy, 91, 25-33. https://doi.org/10.1016/j.eja.2017.09.009

Reijonen, I., Metzler, M., \& Hartikainen, H. (2016). Impact of soil pH and organic matter on the chemical bioavailability of vanadium species: The underlying basis for risk assessment. Environmental Pollution, 210, 371-379. https://doi.org/10.1016/j.envpol.2015.12.046

Robertson, G. P., \& Vitousek, P. M. (2009). Nitrogen in Agriculture: Balancing the Cost of an Essential Resource. Annual Review of Environment and Resources, 34(1), 97-125. https://doi.org/10.1146/annurev.environ. 032108.105046

Robinson, N., Brackin, R., Vinall, K., Soper, F., Holst, J., Gamage, H., ... Schmidt, S. (2011). Nitrate Paradigm Does Not Hold Up for Sugarcane. PLoS One, 6(4), e19045. https://doi.org/10.1371/journal.pone. 0019045.t001 
Sileshi, G. W., Debusho, L. K., \& Akinnifesi, F. K. (2012). Can Integration of Legume Trees Increase Yield Stability in Rainfed Maize Cropping Systems in Southern Africa? Agronomy Journal, 104(5), 1392. https://doi.org/10.2134/agronj2012.0063

Solanki, M. K., Wang, Z., Wang, F. Y., Li, C. N., Lan, T. J., Singh, R. K., \& Li, Y. R. (2016). Intercropping in Sugarcane Cultivation Influenced the Soil Properties and Enhanced the Diversity of Vital Diazotrophic Bacteria. Sugar Tech, 19(2), 136-147. https://doi.org/10.1007/s12355-016-0445-y

Song, Y. N., Marschner, P., Li, L., Bao, X. G., Sun, J. H., \& Zhang, F. S. (2007a). Community composition of ammonia-oxidizing bacteria in the rhizosphere of intercropped wheat (Triticum aestivum L.), maize (Zea mays L.), and faba bean (Vicia faba L.). Biology and Fertility of Soils, 44(2), 307-314. https://doi.org/ $10.1007 / \mathrm{s} 00374-007-0205-\mathrm{y}$

Song, Y. N., Zhang, F. S., Marschner, P., Fan, F. L., Gao, H. M., Bao, X. G., \& Li, L. (2007b). Effect of intercropping on crop yield and chemical and microbiological properties in rhizosphere of wheat (Triticum aestivum L.), maize (Zea mays L.), and faba bean (Vicia faba L.). Biology and Fertility of Soils, 43(5), 565-574. https://doi.org/10.1007/s00374-006-0139-9

Tomes, D., Lakshmanan, P., \& Songstad, D. (2011). Biofuels (p. 357). Springer, New York. https://doi.org/ 10.1007/978-1-4419-7145-6

Tsiknia, M., Tzanakakis, V. A., Oikonomidis, D., Paranychianakis, N. V., \& Nikolaidis, N. P. (2013). Effects of olive mill wastewater on soil carbon and nitrogen cycling. Applied Microbiology and Biotechnology, 98(6), 2739-2749. https://doi.org/10.1007/s00253-013-5272-4

Urbanová, M., Šnajdr, J., \& Baldrian, P. (2015). Composition of fungal and bacterial communities in forest litter and soil is largely determined by dominant trees. Soil Biology and Biochemistry, 84, 53-64. https://doi.org/ 10.1016/j.soilbio.2015.02.011

Vance, E. D., Brookes, P. C., \& Jenkinson, D. S. (1987). An extraction method for measuring soil microbial biomass C. Soil Biology and Biochemistry, 19(6), 703-707. https://doi.org/10.1016/0038-0717(87)90052-6

Vandermeer, J. (2011). The Ecology of Agroecosystems. Jones and Bartlett Publishers, Sudbury, MA, USA. Waddington, S.R., Mekur.

Walkley, A. (1935). An Examination of Methods for Determining Organic Carbon and Nitrogen in Soils. (With One Text-figure.). The Journal of Agricultural Science, 25(04), 598. https://doi.org/10.1017/s0021859 600019687

Wang, Z. G., Jin, X., Bao, X. G., Li, X. F., Zhao, J. H., Sun, J. H., ... Li, L. (2014). Intercropping Enhances Productivity and Maintains the Most Soil Fertility Properties Relative to Sole Cropping. PLoS One, 9(12), e113984. https://doi.org/10.1371/journal.pone.0113984

Weerarathne, L. V. Y., Marambe, B., \& Chauhan, B. S. (2017). Intercropping as an effective component of integrated weed management in tropical root and tuber crops: A review. Crop Protection, 95, 89-100. https://doi.org/10.1016/j.cropro.2016.08.010

Yang, Z., Yang, W., Li, S., Hao, J., Su, Z., Sun, M., \& Zhang, C. (2016). Variation of bacterial community diversity in rhizosphere soil of sole-cropped versus intercropped wheat field after harvest. PloS One, 11(3), e0150618. https://doi.org/10.1371/journal.pone.0150618

Yu, Y., Stomph, T. J., Makowski, D., \& van der Werf, W. (2015). Temporal niche differentiation increases the land equivalent ratio of annual intercrops: A meta-analysis. Field Crops Research, 184, 133-144. https://doi.org/10.1016/j.fcr.2015.09.010

Yu, Y., Stomph, T. J., Makowski, D., Zhang, L., \& van der Werf, W. (2016). A meta-analysis of relative crop yields in cereal/legume mixtures suggests options for management. Field Crops Research, 198, 269-279. https://doi.org/10.1016/j.fcr.2016.08.001

Zeng, Y., Huang, J. S., Xie, R. L., Zhou, L. Q., Liu, Y. X., Tan, Y. M., \& Tan, H. W. (2015). Survey and Study of Soil Nutrients of Sugarcane Field in Southern Guangxi. Asian Agricultural Research, 7(6), 56-65.

Zhang, F., \& Li, L. (2003). Using competitive and facilitative interactions in intercropping systems enhances crop productivity and nutrient-use efficiency. Plant and Soil, 248(1/2), 305-312. https://doi.org/ 10.1023/a:1022352229863 
Zhang, Q. M., Zhu, L. S., Wang, J., Xie, H., Wang, J. H., Wang, F., \& Sun, F. X. (2014). Effects of fomesafen on soil enzyme activity, microbial population, and bacterial community composition. Environmental Monitoring Assessment, 186, 2801-2812. https://doi.org/10.1007/s10661-013-3581-9

\section{Copyrights}

Copyright for this article is retained by the author(s), with first publication rights granted to the journal.

This is an open-access article distributed under the terms and conditions of the Creative Commons Attribution license (http://creativecommons.org/licenses/by/4.0/). 